\title{
Quantitative CT parameters correlate with lung function in chronic obstructive pulmonary disease: a systematic review and meta-analysis
}

\section{Yan Wang}

Qinghai University

Shan Lin

Lanzhou University

Jian-Ting Li

Qinghai University

Jing Wu

Qinghai University

Dong Han

Shaanxi Provincial People's Hospital

Wei Guan ( 664534200@qq.com )

https://orcid.org/0000-0002-1080-0509

Research article

Keywords: Airway obstruction, Systematic review, Meta-analysis

Posted Date: June 19th, 2019

DOl: https://doi.org/10.21203/rs.2.10454/v1

License: (1) This work is licensed under a Creative Commons Attribution 4.0 International License.

Read Full License 


\section{Abstract}

Background The aim of the study was to analyze the correlation between quantitative computed tomography (CT) parameters and airflow obstruction in patients with chronic obstruction pulmonary disease (COPD). Methods PubMed, Embase, Cochrane and Web of Knowledge were searched by two investigators from inception to 2018 , using a combination of pertinent items to discover articles that investigated the relationship between CT measurements and lung function parameters in patients with COPD. Five reviewers independently evaluated the quality, extracted data and evaluated bias. The correlation coefficient was calculated and heterogeneity was explored. The following CT measurements were extracted: percentage of lung attenuation area <-950 Hounsfield Units (HU), mean lung density, percentage of airway wall area, air trapping index, airway wall thickness. Two airflow obstruction parameters were extracted: forced expiratory volume in the first second as a percentage of prediction (FEV1\% pred) and FEV1 divided by forced expiratory volume lung capacity. Results A total of 117 studies $(19,942$ participants) were identified, 36 of which (4,762 participants) were suitable for meta-analysis. Results from our analysis demonstrated that there was a significant correlation between quantitative CT parameters and lung function. The absolute pooled correlation coefficients ranged from $0.44(95 \% \mathrm{Cl}$, 0.36 to 0.53 ) to $0.71(95 \% \mathrm{Cl}, 0.65$ to 0.77$)$ for inspiratory $\mathrm{CT}$ and $0.59(95 \% \mathrm{Cl}, 0.53$ to 0.65$)$ to 0.66 ( $95 \%$ $\mathrm{Cl}, 0.61$ to 0.72 ) for expiratory CT. Conclusions Results from this analysis demonstrated that quantitative CT parameters are significantly correlated with lung function in patients with COPD. With recent advances in chest CT, we can evaluate morphological features in the lungs that cannot be obtained by other clinical indices, such as pulmonary function tests. Therefore, CT can provide a quantitative method to advance the development and testing of new interventions and therapies for patients with COPD .

\section{Background}

Chronic obstructive pulmonary disease (COPD) is a common inflammatory lung disease characterized by persistent respiratory symptoms and airflow limitation due to airway and/or alveolar abnormalities[1,2].There is a high incidence of COPD worldwide and it is currently the fourth leading cause of death in the world. However, it is expected to become the third leading cause of death by 2020[3].Studies have also suggested that COPD has become the third most common chronic disease after diabetes and hypertension in China[4]. In addition, COPD has a long course and progressive development. The treatment effect of advanced COPD is poor and the disability rate is high, which seriously affects the quality of life. At present, COPD has become a global public problem that requires urgent resolution[5].Therefore, accurate evaluations of the conditions of patients with COPD are necessary in order to select the correct treatment plans and improve the conditions of patients. Although the majority of patients followed a path of disease progression in which the severity of COPD tracked the severity of airflow limitation, the conventional method (such as pulmonary function tests, PFTs) fail to provide - information about regional pulmonary dysfunction[6]. In addition, PFTs require the cooperation of patients to obtain reliable data, and this is not always achievable with pediatric patients and patients with cognitive impairment, hearing impairment and advanced pulmonary disease. The thought-provoking 
question in recent years has been more than just what lung function can do, but how credible it is. Studies have shown that the use of the fixed forced expiratory volume in the first second/ forced vital capacity $\left(F E V_{1} / F V C\right.$ ) ratio to define airflow limitation may result in more frequent diagnoses of COPD in the elderly, and less frequent diagnoses in adults $<45$ years of age (especially in patients with mild COPD), as compared with the use of the low limit of normal (LLN) values for $\mathrm{FEV}_{1} / \mathrm{FVC}[7,8]$. However, from a scientific or clinical perspective, it is difficult to determine if the criteria of LLN will result in optimal diagnostic accuracy for COPD. Additionally, studies have shown that $\mathrm{FEV}_{1}$ is only weakly correlated with the severity of symptoms and health status of patients with $\operatorname{COPD}[9,10]$. Further, the predictive value of $\mathrm{FEV}_{1}$ for the risk of future acute exacerbation is very low. When using COPD Assessment Test (CAT) or Modified Medical Research Council (mMRC) grouping, the grading results were inconsistent, and the risk and all-cause mortality of patients with grade B COPD were higher than those of patients with grade $C$ COPD[11]. Thus, the 2017 Global initiative for Chronic Obstructive Lung Disease (GOLD) guide to the comprehensive assessment of chronic obstructive pulmonary disease was amended, and lung functioning was graded separately from the assessment tool. As a result of these changes, the number of patients with COPD has been underestimated, and recent studies have suggested that changes to the GOLD guidelines have affected the whole 2017 comprehensive evaluation of COPD, high-risk population is more than a third of the regrouping to low risk category[12-15]. That is, it is controversial to use pulmonary function to diagnose and evaluate the severity of COPD. However, because of the maneuverability and repeatability of pulmonary function, we still use pulmonary function as a diagnostic criterion of COPD. However, from the point of scientific research, an objective index should be developed to prevent missed diagnoses, excessive medical treatment, and underestimation of the disease.

With the rapid development of $\mathrm{CT}$ imaging technology, there has been a dramatic reduction in the radiation burden associated with $\mathrm{CT}$ in recent years, and a diagnostic improvement compared with classical chest X-ray[16]. Through objective quantitative evaluation of pulmonary emphysema and airways disease, CT may help achieve clinically meaningful phenotyping. Quantitative imaging has provided repeatable and unbiased estimates of the severity and distribution of lung pathology[17].

In recent years, many studies that have investigated the correlation between lung function and quantitative CT have been conducted, but there is still a lack of convincing multi-center studies[18-21]. Therefore, we conducted a systematic review and meta-analysis to guide the clinical analysis and treatment of patients with COPD .

\section{Materials And Methods}

The study was designed according to the Preferred Reporting Items for Systematic Reviews and MetaAnalyses (PRISMA) statement[22]. Since this meta-analysis only used data from published studies, no ethical approval was provided.

\section{Data sources and searches}


PubMed, Embase, Cochrane and Web of Knowledge were searched for articles published from their inception to December 2018, using a combination of pertinent items to discover articles that investigated the relationship between CT measurements and lung function parameters in patients with COPD.

Language restrictions were not implemented. Meanwhile, manual retrieval was also carried out. Generally, the literature search was conducted using three keywords, such as 'chronic obstructive pulmonary disease', 'pulmonary function test', and 'CT'. Besides, the Boolean operator 'AND' was used in these three sets of keywords, and 'OR' was used within each group. The detailed search process is shown in Supplementary Table 1. To obtain a comprehensive retrieval of the literature, we also scanned all the bibliographies of the relevant publications, as well as related comments. When the required data were ambiguous or missing, we contacted the authors.

\section{Study selection}

Each study was evaluated independently and systematically by five investigators with more than 6 years of thoracic radiology related working experiences. Articles were included in the systematic review if they met the following criteria: (1) all patients with COPD were $\geq 18$ years old, human beings, without a history of dementia; (2) interventions included participants who had clearly described PFT, according to the guidelines of the American Thoracic Society (ATS), the European Respiratory Society (ERS), or other similar methods; (3) the relationship between quantitative CT and PFT was analyzed; (4) patients with stable COPD could be diagnosed according to strict criteria, such as GOLD, ATS or ERS, without changes in medication or acute exacerbation within the pass 6 weeks; (5) and the methods of the study included randomized control trial (RCTs), observational (prospective and retrospective cohort) studies, and crosssectional studies. In addition, the exclusion criteria were as follows: (1)case reports, letters, and conference abstracts; (2) studies with outcomes from only PFT or quantitative CT; (3) participants who were included in other studies within the past 6 weeks; (4) participants with other confounding diseases (such as interstitial lung disease, chronic bronchitis, a-1 anti-trypsin, asthma, lung cancer, other lung surgery, active pulmonary tuberculosis, ect.); (5) and participants with diseases that affected adequate breathing (such as pericardial effusion, pleural effusion, and arterial oxygen saturation $<90 \%$ at rest).

Articles were included in the meta-analysis if (1) the study included a comparable proportion of GOLD 1-4 grades patients; (2) had a sample size $\geq 20$ (20 subjects would provide a power of 0.90 when detecting a typical effect correlation coefficient (CC) of 0.60); (3) provided the percentage of lung attenuation area under -950 HU (\%LAA $\leq 950)$, mean lung density (MLD), wall area percentage (WA\%) in airways $\geq$ fifth airway generation, air trapping index $₫ A T I)$ \airway wall thickness $₫ \mathrm{WT} \otimes$, and airway lumen area (Al) by volumetric multi-detector CT (MDCT); (4) CCs of lung function and quantitative CT; (5) and parameters of lung function included the predicted forced expiratory volume in the first second as percentage ( $F E V_{1} \%$ pred) and $\mathrm{FEV}_{1}$ divided by the forced volume vital capacity $\left(\mathrm{FEV}_{1} / \mathrm{FVC}\right)$. Articles were excluded in the meta-analysis if: (1)the relevant data were ambiguous or missing, and we could not contact the authors and; (2) the CT examination only provided selected pulmonary levels or the slice increment was 
larger than the thickness. If duplicate data was used, the study with the largest sample was included in the analysis.

\section{Data extraction and quality assessment}

Two reviewers independently screened articles for fulfillment of inclusion and exclusion criteria. Any disagreements or discrepancies were resolved through a consensus. Data tables were made to extract all relevant data from texts, tables, and figures of each study, including study characteristics, participant characteristics, methodology, and CCs. \%LAA-950, MLD, 15 percentile point of lung density (Perc 15), lung volume (LV), WA\%, WT, AI , and ATI were recorded in the systematic review. Six CT measurements including \% LAA-950, MLD, WA\%, WT, Al, and ATI, were pooled in the meta-analysis, and two PFT parameters including $\mathrm{FEV}_{1} \%$ pred and $\mathrm{FEV}_{1} / \mathrm{FVC}$ were extracted.

Furthermore, the Quality Assessment of Diagnostic Accuracy Studies (QUADAS) tool[23]was used for study methodological quality and potential bias. A study with a QUADAS score $\geq 11$ points was deemed as high quality, while a study with a score $₫ 11$ was considered to be of low quality.

\section{Data synthesis and analysis}

The overall measure was the correlation coefficient (CC) between CT and PFT parameters. The HedgesVevea random effects model and normality Z-test were used to calculate the pooled $95 \%$ confidence intervals (95\% Cls). We calculated the correlation between \%LAA-950 and FEV $\%$ pred, \%LAA-950 and

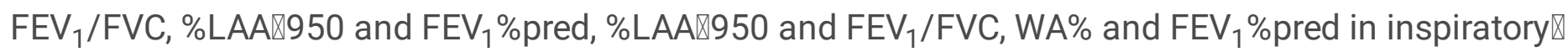
MLD and $F E V_{1} \%$ pred, MLD and $F E V_{1} / F V C$, ATI and $F E V_{1} / F V C$, WT and $\mathrm{FEV}_{1} \%$ pred, WT and $\mathrm{FEV}_{1} / \mathrm{FVC}$, Al and $\mathrm{FEV}_{1} \%$ pred, $\mathrm{Al}$ and $\mathrm{FEV}_{1} / \mathrm{FVC}$, \%LAA-950 and $\mathrm{FEV}_{1} \% \operatorname{pred}(\mathrm{GE})$, and \%LAA-950 and FEV $1 \%$ pred (Siemens, Toshiba, and Philips). If evaluating multiple layers of bronchi, we chose the smallest bronchi. Heterogeneity was evaluated using the $\mathrm{I}^{2}$ index. Additionally, we used a random effects model rather than a fixed effect model because the former was better equipped to explain the heterogeneity between the studies. Subgroup analyses were used to determine the impact of individual variables and the potential sources of heterogeneity. Also, the potential publication bias was assessed using the Begg's test.

In addition, we divided the radiation doses into $950 \mathrm{HU}$ and $<950 \mathrm{HU}$ (such as $910 \mathrm{HU}, 900 \mathrm{HU}$ ) and divided breath-holding procedures into inspiratory and expiratory. We also divided CT machines into GE and Siemens, Toshiba, and Philips. All statistical analyses were performed using Stata 15.0 and SPASS 18.0. Further, sensitivity analyses were conducted to assess the impact of each study on the results of the pooled study by eliminating each study. Finally, analysis trimming and filling were carried out if necessary.

\section{Results}




\section{Study selection}

From the electronic databases (PubMed, Embase, Cochrane and Web of Knowledge), a total of 2208 studies were included (Supplementary Figure 1), and1961 citations were excluded based on their titles or abstracts. After screening the text of 247 articles, 130 studies were excluded from the systematic review. The reasons for exclusion were that the studies did not include: a large enough COPD sample or there was not association between quantitative CT and PFTs. According to the exclusion criteria of the metaanalysis, 81 studies were excluded. The reasons for exclusion were as follows: (1) selection bias, (2) small sample size, (3) MDCT volume scans were not available, (4) quantitative CT parameters were not included, and (5) PFT parameters were not included. Finally, 117 articles were used for systematic review and 36 articles were included in the meta-analysis.

\section{Systematic review}

The systematic review included a total of 1, 9942 participants. The age of patients range from $40-80$, and there were 1, 2252 (61.4\%) men, 5676 (28.5\%) women, 2014 (10\%) of the participants did not specify their gender (Supplementary Table 2). This study included RCTs and cohort studies. Of these, articles $51.6 \%$ (61 articles) were from Europe, 29.9\% (35 articles) were from Asia, 14.5\% (17 articles) were from North America, 3.4\% (4 articles) from Oceania. Further, 106 (90.6\%) were written in English, 5 (4.2\%) in Italian, $4(3.4 \%)$ in Chinese, 1 (0.9\%) in French, and 1 (0.9\%) in Polish.

The sample sizes of the recent publications were significantly larger than before, and the CT equipment was more advanced (Supplementary Figure. 2). Articles included a variety of breath-holding procedures, such as only inspiratory, expiratory, or both inspiratory and expiratory.

The selected articles included 75 quantitative CT parameters and 27 pulmonary function parameters (Supplementary Figure 4 and Figure 5), and the final parameters for the systemic review included \%LAA950, MLD, WA\% , ATI, WT, Al, FEV F $_{1}$ pred, and FEV $1 /$ FVC. The common threshold defining the lung parenchyma in emphysema was -900 to $-960 \mathrm{HU}$, and the most commonly used threshold was -950 $\mathrm{HU}[24]$. In some study, different thresholds in the same sample had different correlations with airflow obstruction parameters in PFT $[18,20,35,40]$. The broad range of published CCs between CT and PFT parameters were as follow: \%LAA-950 and FEV 1 \%pred, -0.66 to $-0.09[18,19] ; \%$ LAA-950 and FEV 1 /FVC,

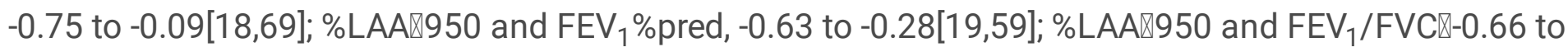
$-0.54[19,35]$;WA\% and FEV ${ }_{1} \%$ pred, -0.713 to $-0.044[30,70]$;MLD and $\mathrm{FEV}_{1} \%$ pred, 0.18 to 0.85 [18,68]; MLD and $\mathrm{FEV}_{1} / \mathrm{FVC}, 0.21$ to $0.89[18,19] ; \mathrm{ATI}$ and $\mathrm{FEV}_{1} \%$ pred, -0.725 to $-0.29[41,48] ; \mathrm{WT}$ and $\mathrm{FEV}$ \%pred, -0.68 to -0.13[33,35]; WT and FEV 1 /FVC, -0.62 to $-0.05[33,35]$; Al and FEV ${ }_{1} \%$ pred, 0.73 to 0.14[28,33]; Al and $\mathrm{FEV}_{1} / \mathrm{FVC}, 0.32$ to $0.07[33,46] ; \% \mathrm{LAA}-950$ and $\mathrm{FEV}_{1} \%$ pred by GE, -0.67 to $-0.43[26,60]$; \%LAA-950 and FEV $_{1} \%$ pred by non-GE (such as Siemens, Toshiba, and Philips), -0.67 to $-0.43[39,47]$ (Supplementary Table 3). 


\section{Risk of bias in the meta-analysis}

All articles included in the meta-analysis were high quality; QUADAS scores ranged from 12.5 to 13.5(Supplementary Table 4 and Supplementary Figure 6). Generally, the risk of bias was assessed by reviewers using a recognized bias tool. QUADAS 2 where CT density was being considered as a diagnostic tool. Funnel plots and Begg-Mazumdar/Egger tests were selected to assess publication bias and reduce bias by excluding date or language limits during our search. No publication bias was found ( supplementary Table 5).

Several of the meta-analyses showed slight heterogeneity. The $\mathrm{I}^{2}$ index was $>50 \%$ for correlations between $\mathrm{WA} \%$ and $\mathrm{FEV}_{1} \%$ pred in inspiration $\left(\mathrm{P}=0.017, \mathrm{I}^{2}\right.$ index $\left.=61.1 \%\right)$, WT and $\mathrm{FEV}_{1} / \mathrm{FVC}$ in inspiration $\left(P=0.000, I^{2}\right.$ index $\left.=96.1 \%\right)$, Al and $F V_{1} \%$ pred in inspiration $\left(P=0.000, I^{2}\right.$ index $\left.=90.7 \%\right)$, and $\mathrm{Al}$ and $\mathrm{FEV}_{1} / \mathrm{FVC}$ in inspiration $\left(\mathrm{P}=0.031, \mathrm{I}^{2}\right.$ index $\left.=71.1 \%\right)$.

\section{Synthesis of results in the meta-analysis}

A total of 4762 participants were included in the meta-analysis (Supplementary Fig. 3). The CC between \%LAA-950 and FEV1\%pred in inspiration was reported in 24 articles [19,26-28,30-32,34-37,39,41,4547,50,52-54,57-60]. Two [27,33]National Lung Screening Test (NLST) cohorts and three [30,31,51]Korean Obstruction Lung Disease (KOLD) cohorts were performed. The pooled CC between \%LAA-950 and $\mathrm{FEV}_{1} \%$ pred was $-0.51(-0.56,-0.47),-0.59(-0.65,-0.53)$ in inspiration and expiration, respectively. The pooled CC between \%LAA $₫ 950$ and $\mathrm{FEV}_{1} / \mathrm{FVC}$ was $-0.64(-0.68,-0.59),-0.66(-0.72,-0.61)$ in inspiration and expiration, respectively.

Ten articles $[26,28-30,33,36,47,55,57,62]$ reported CCs between WA\% and FEV ${ }_{1} \%$ pred in inspiration. Two articles $[26,30]$ were excluded because airway measurements only involved airway above the fifth generation. Another article ${ }^{33}$ was excluded because it did not report which airway were measured, making data extraction difficult. Therefore, a total of 7 articles were included $[28,29,36,47,55,57,62]$.In the included literature, the average lumen diameter of the peripheral airway was about $2-3 \mathrm{~mm}$. The pooled CC value between WA\% and $\mathrm{FEV}_{1} \%$ pred was $-0.46(95 \% \mathrm{Cl}:-0.55,-0.38)$ in inspiration. Expiratory CT was not used for airway measurements.

No duplicate reports were found when extracting data related to MLD. The CC between MLD and $\mathrm{FEV}_{1} \%$ pred was reported in five articles $[30,35,36,48,67]$. Two $[48,67] \mathrm{KOLD}$ cohorts were excluded because the article quality scores were not high and the post-CT processing method was different than that used in the other studies. Three articles $[30,35,36]$ were included. The pooled CC between MLD and $\mathrm{FEV}_{1} \%$ pred was $0.44(95 \% \mathrm{Cl}: 0.36,0.53)$ and MLD and $\mathrm{FEV}_{1} / \mathrm{FVC}$ was $0.54(95 \% \mathrm{Cl}$ : $0.39,0.68)$ in inspiration. 
Only three studies $[41,48,51]$ were analyzed according to strict criteria for inclusion. From these studies, we determined that the pooled CC between ATI and FEV 1 /FVC was $-0.71(95 \% \mathrm{Cl}:-0.77,-0.65)$ in inspiration. This study did not analyze $\mathrm{ATI}$ and $\mathrm{FEV}_{1} \%$ pred because few articles included this information.

Three articles $[33,38,56]$ reported CCs between WT and FEV ${ }_{1} \%$ pred in inspiration. The pooled CC between WT and FEV $\mathrm{Fpred}_{1}$ was -0.15 (95\% Cl: $\left.-0.25,-0.05\right)$ in inspiration, and the pooled CC of WT and FEV 1 /FVC was $-0.33(95 \% \mathrm{Cl}:-0.69,0.02)$ in inspiration.

Five articles $[29,33,36,56,62]$ reported CCs between Al and FEV ${ }_{1} \%$ pred in inspiration. However, Al and $\mathrm{FEV}_{1} / \mathrm{FVC}$ only had three groups of data, and the heterogeneity of this data was relatively large, it was

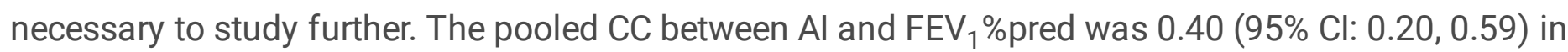
inspiration, and the pooled CC of $\mathrm{Al}$ and $\mathrm{FEV}_{1} / \mathrm{FVC}$ was $0.21(95 \% \mathrm{Cl}: 0.07,0.35)$ in inspiration.

Eight articles $[26,28-30,33,36,47,55,57,62]$ reported CCs between LAA-950 and FEV ${ }_{1} \%$ pred using GE in inspiration. Five articles $[31,39,47,50,54]$ reported CCs between LAA-950 and FEV ${ }_{1} \%$ pred using other brands of CT machines (such as Siemens, Toshiba, and Philips) in inspiration. The pooled CC between LAA-950 and FEV ${ }_{1} \%$ pred using GE was -0.50 (95\% Cl: $\left.-0.56,-0.45\right)$ and $-0.59(95 \% \mathrm{Cl}:-0.65,-0.53)$ between LAA-950 and $\mathrm{FEV}_{1} \%$ pred using other brands of CT machines.

\section{Subgroup analysis}

We performed a subgroup analysis, depending on the radiation dose. At $₫ 950$ doses (such as $-910 \mathrm{HU}$, $-900 \mathrm{HU}$ ), the pooled CC was -0.64 ( $95 \% \mathrm{Cl}:-0.68,-0.59)$. At doses of $950 \mathrm{HU}$, the pooled CC was -0.51 (95\% $\mathrm{Cl}:-0.56,-0.47)$. There was no significant difference between \%LAA-950 and FEV ${ }_{1}$ pred $(P>0.05)$. Subgroup analysis was performed for inspiratory and expiratory CT. Compared with inspiratory CT, expiratory CT \%LAA-950 showed a stronger negative correlation with $\mathrm{FEV}_{1} \%$ pred $(\mathrm{P}<0.05), \mathrm{MLD}$ and $\mathrm{FEV}_{1}$ \%pred showed a stronger positive correlation $(\mathrm{P}<0.001)$, but there were no significant correlations between \%LAA-950 and $\mathrm{FEV}_{1} / \mathrm{FVC}$, or $\mathrm{MLD}$ and $\mathrm{FEV}_{1} / \mathrm{FVC}(\mathrm{P}>0.05)$. Subgroup analyses were also performed based on the brands of CT machines. The pooled CC was $-0.50(95 \% \mathrm{Cl}:-0.56,-0.45)$ in the first group (GE) and -0.59 (95\% Cl: -0.65,-0.53) in the second group (Siemens, Toshiba, and Philips). That is, there was no significant difference between \%LAA-950 and FEV ${ }_{1} \%$ pred according to CT machine $(\mathrm{P}$ > 0.05) (supplementary table 5).

\section{Discussion}

In the current study, we conducted a systematical review and meta-analysis to determine the relationship between quantitative CT parameters and airflow obstruction in patients with COPD. The results of this meta-analysis suggested that there were correlations between inspiratory and expiratory CT parameters and PFTs parameters in patients with COPD. In the included studies, the absolute CCs of CT measurements and airflow limitation were as follows: inspiratory CT, 0.44 to 0.71 and expiratory CT, 0.59 
to 0.66 . These results were consistent with other studies that have revealed that expiratory CT can be used as an auxiliary examination for inspiratory CT. This reconfirmed our hypothesis that there was a significant correlation between the proportion of emphysema, MLD, Al, ATI, WT, and lung function in patients with COPD. Therefore, this approach generates reproducible and sensitive measurements of COPD related to pulmonary ventilation and perfusion and airway and parenchyma anatomical and morphological features.

Pulmonary function is the main objective test for determining airflow limitation. $\mathrm{FEV}_{1} / \mathrm{FVC}$ can detect mild airflow obstruction, which is beneficial for early detection and treatment of patients with COPD. However, lung function does not provide information on regional dysfunction. With the widespread use of quantitative $\mathrm{CT}$ and the continuous improvement of corresponding software, lung structure and function abnormalities can be regionally identified and measured. \%LAA-950 and MLD can reflect the extent of damage to the lung parenchyma. Meanwhile, it can be used to measure the thickness of the bronchial wall to assess the degree of airflow obstruction. Thus, quantitative CT is a comparatively superior method for identifying morphological information regrading the degree of airway stenosis and the proportion of emphysema, which are complementary to lung function.

This systematic review included $\geq 10$ different CT measurements. However, because of the insufficient number of studies, only 6 items (\%LAA-950, \%LAA 950 MLD, WA\%, Al, ATI, and WT) were used in the meta-analysis. We also evaluated $\mathrm{FEV}_{1} / \mathrm{FVC}$ and $\mathrm{FEV}_{1} \%$ pred from PFTs because these are important factors associated with the diagnosis of COPD and the classification of airflow limitation. Furthermore, the above two parameters were relatively comprehensive and easy to extract.

We performed a subgroup analysis based on different respiratory processes (including inspiratory and expiratory processes). Our results demonstrated that CT measurements in expiratory were more strongly correlated with $\mathrm{FEV}_{1} \%$ pred than inspiratory, but less correlated with $\mathrm{FEV}_{1} / \mathrm{FVC}$ in expiratory than in inspiratory $[19,20,34]$. This was consistent with other findings have suggested that CT measurements in expiratory are more strongly correlated with airflow limitation than in inspiratory [63-65]. However, the significance of expiratory CT data for the assessment of COPD still requires additional data for further study. Further, we also performed a subgroup analysis according to the brand of CT machines, and the results indicated that \%LAA-950 was correlated with lung function regardless of the brand of CT machine, which was consistent with previous studies by imaging experts [24]. Meanwhile, studies have shown that low radiation doses (which provides protection for patients) do not alter the correlation between CT emphysema quantification and airflow limitation compared to normal doses. While the prolonged examination time also reminded us to perform adequate breathing training for patients before CT examination.

Some researchers have studied the third to fifth or sixth generation airways and found that the correlation between airway wall measurements and PFT was stronger in the smallest airways $[24,28,36]$. In order to reduce the deviation caused by different airway generations, we unified $\geq 5^{\text {th }}$ generation airways and included them in the meta-analysis. From our results, the correlation between $\mathrm{WA} \%$ and $\mathrm{FEV}_{1} \%$ pred was 
-0.47. Based on the above results, the airway WT measurement from CT was more reliable in the smallest airway.

Although some previous meta-analyses [20,21,25,63]have evaluated the relationship between quantitative CT and lung function in patients with COPD, the current meta-analyses reconfirmed these finding and had multiple advantages. First of all, this meta-analysis had a large sample size, which made our results more reliable. Second, all included studies had more quantitative CT parameters, such as WT and Al. Subgroup analyses were also performed according to the radiation dose (\%LAA-950HU, 910HU, and 900HU) and the brands of CT machines. These comparisons have often been overlooked in previous studies and we found that there are many brands of CT machines (such as GE, Siemens, Toshiba and Philips). Therefore, it is necessary to conduct subgroup analyses to determine if brands of CT machines impact the results. Third, the results of most studies were highly consistent. After sensitivity analysis and publication bias analysis, the source of heterogeneity has been found, which provides ideas for future experimental designs. Fourth, our results enriched and validated the previous conclusions.

Meanwhile, this meta-analysis inevitably had some limitations. First, the results of this study may be influenced by the age, race, and the male-female ratio.Additionally, the severity of the disease varied among participants in the included studies. Second, some of the research data were obviously wrong or lost, therefore we did not extracted them, and this led to a further reduction in sample size. Third, a variety of quantitative CT parameters and PFT parameters were extracted for systematic evaluation but only representative parameters with complete data were selected for the meta-analysis. Measurements that were not included may be valuable for the evaluation of COPD, and these measurements require further research. Above all, the interval time between lung function and quantitative CT was inconsistent, and this may have impacted the measurements of quantitative CT parameters. In addition, we used different brands of CT machines, post-processing software, work stations that we did not examine in more details because their impact was considered less relevant [24]. This study also conducted a subgroup analysis according to the brands of CT machines, and the results showed that quantitative CT parameters were correlated with lung function regardless of the brands of CT machines. Thus, this systematic review was based on studies of high methodological quality, and there was no publication bias, therefore the results have a certain strength of argumentation.

\section{Conclusions}

Results from this study provided evidence that quantitative CT parameters are significantly correlated with lung function in patients with COPD. These results also showed the proportion of emphysema and air trapping in expiratory. CT parameters were used as a complementary diagnostic tool for PFTs. Quantitative CT may provide an independent approach for assessing obstructive pulmonary diseases and should be used in combination with PFTs for accurate and early diagnosis of COPD and testing new interventions and therapies for patients with COPD.

\section{Abbreviations}


\%LAA $\leq$ 950: Percentage of lung attenuation area under -950 HU; Al: Airway lumen area; ATI: Air trapping index; ATS: American Thoracic Society; CC: correlation coefficient; Cl: Confidence interval; COPD: Chronic obstructive pulmonary disease; CT: Computed tomography; ERS: European Respiratory Society; $\mathrm{FEV}_{1}$ \%pred: Forced expiratory volume in the first second as percentage from predicted; $\mathrm{FEV}_{1} / \mathrm{FVC}$ : FEV 1 divided by the forced volume vital capacity; GOLD: Global initiative for chronic Obstructive Lung Disease; HU: Hounsfield unit; LV: Lung volume; MLD:Mean lung density; PFT: Pulmonary function test; PRISMA: Preferred Reporting Items for Systematic Reviews and Meta-analyses; QUADAS: Quality Assessment of Diagnostic Accuracy Studies; WA\%: Wall area percentage; WT: Airway wall thickness.

\section{Declarations}

\section{Acknowledgements}

We thank Jian-ting Li $₫ \mathrm{MM} \otimes \mathbb{D}$ epartment of Burn and Plastic Surgery, Affiliated Hospital of Qinghai University, Xining, China冈for his technical assistance and general support.

We thank Professor Wei Guan, who is specialized in biomedical writing and editing, for copyediting this manuscript.

\section{Funding}

This study was supported by Health Commission of Qinghai Province, Medicine Science and Technology Project (No.2017-wjzd-11).

\section{Availability of data and materials}

The data supporting our findings can be found by contacting with us (weiguan110@163.com).

\section{Authors' contributions}

Yan Wang $\llbracket$ Shan Lin and Wei Guan conceived and designed the paper. Yan Wang, Shan Lin were responsible for all data gathering, extraction, and analysis. Dong Han was the primary independent reviewer, with bias and quality of data extraction reviewed by Shan Lin ,Wei Guan and Jing Wu. All authors contributed toward data analysis, drafting and revising this paper and agree to be accountable for all aspects of the work.

\section{Ethics approval and consent to participate}


Not applicable. There is no ethical approval, because we only use published stuies data for Metaanalysis.

\section{Consent for publication}

Not applicable.

\section{Competing interests}

The authors declare that they have no competing interests.

\section{Publisher's Note}

Springer Nature remains neutral with regard to jurisdictional claims in published maps and institutional affiliations.

\section{Author details}

${ }^{1}$ Department of Respiratory Medicine, Qinghai University Affiliated Hospital, Xining, 810001, China.

${ }^{2}$ Department of Respiratory and Critical Care Medicine, The First Hospital of Lanzhou University, Lanzhou, 730050, China. ${ }^{3}$ Department of Burn and Plastic Surgery, Qinghai University Affiliated Hospital, Xining, 810001,China. ${ }^{4}$ Department of Hematology Medicine, Qinghai University Affiliated Hospital, Xining, 810001, China. ${ }^{5}$ Department of Respiratory and Critical Care Medicine, Shaanxi Provincial People's Hospital, Xi'an, 710068, China.

\section{References}

[1] Wedzicha JE. The heterogeneity of chronic obstructive pulmonary disease. Thorax. 2000;55:631-632.

[2] Regan E, Lynch D, Curran-Everett D, Jeffrey L, Curtis J, Austin J, et al. Clinical and radiologic disease in smokers with normal spirometry. JAMA Intern Med. 2015;175(9): 1539-49.

[3] Global strategy for the diagnosis, management and prevention of Chronic Obstructive Lung Disease (updated 2018). Global Initiative for Chronic Obstructive Lung Disease(GOLD). 2018. www.goldcopd. Org.Accessed on February 18, 2015.

[4] Chen W, Jian-ying X, Lan Y, Yongjian X, Xiang-yan Zh, Chunxue B, et al. Prevalence and risk factors of chronic obstructive pulmonary disease in china (the china Pulmonary Health [CPH] study): a national cross-sectional study. Lancet. 2018;391: 1706-1717. 
[5] Mannino DM, Buist AS. Global burden of COPD: risk factors, prevalence, and future trends. Lancet. 2007;370: 765-773.

[6] Le Roux, P. Y.,Siva, S.,Steinfort, D. P, et al.Correlation of 68Ga Ventilation-Perfusion PET/CT with pulmonary function test indices for assessing lung function. Rheumatol Int. 2015;56(11):1718-23.

[7] Van Dijk W, Tan W, Li P, Guo B, Li S, Benedetti A,et al. Clinical relevance of fixed ratio vs lower limit of normal of FEV1/FVC in COPD: patient-reported outcomes from the CanCOLD cohort. Ann Fam Med. 2015;13(1):41-8.

[8] Güder G, Brenner S, Angermann CE, Ertl G, Held M, Sachs AP, et al. GOLD or lower limit of normal definition? A comparison with expert-based diagnosis of chronic obstruction disease in a prospective cohort-study. Respir Res. 2012;13(1):13.

[9] Han M K, Lange P, Anzueto A, Martinez FJ, Jones PW. GOLD COPD categories are not fit for purpose in primary care-author'reply. Lancet Respir Med. 2013;1(1): e17-e18.

[10] Jones PW. Health status and the spiral of decline. COPD. 2009;6(1): 59-63.

[11] Austi A, Hurd S, Jones P, Fabbri LM, Martinez F, Vogelmeier C, et al. FAQs about the GOLD 2011 assessment proposal of COPD: a comparative analysis of four different cohorts. Eur Respir J. 2013;42(5): 1391.

[12] Global strategy for the diagnosis, management and prevention of Chronic Obstructive Lung Disease (updated 2017). Global Initiative for Chronic Obstructive Lung Disease(GOLD). 2017. www.goldcopd. Org.Accessed on April 05, 2017.

[13] Sun L, Chen Y, Wu R, Lu M, Yao W.Change in definition lead to changes in the clinical characteristics across COPD categories according to GOLD 2017: a national cross-sectional survey in china. Int J Chron Obtruct Pulmon Dis. 2017;3095-3102.

[14] Carlos C, Ciro CM, Jose M, Mario T. Comparison of 2017 and 2015 Globle Initiative for Obstructive Lung Disease: Impact on Grouping and Outcome. AJRCCM Articles in press. 2017;201707-13630C.

[15] Tudoric N, Koblizek V, Miravitlles M, Valipour A, Milenkovic B, Barczyk A, et al. GOLD 2017 on the way to a phenotypic approach? Analysis from the Phenotypes of COPD in Central and Eastern Europe (POPE) Cohort. Eur Respir. 2017;49:1602518.

[16] Herth FJF, Kirby M, Sieren J, Herth J, Schirm J, Wood S, et al. The Modern Art of Reading Computed Tomography Images of the Lungs: Quantitative CT. Respir. 2018;95 (1): 8-17.

[17] Hackx M, Gyssels E, Severo Garcia T, De Meulder I, Bruyneel M, Van Muylem A, et al.Variability of CT airways measurements in COPD patients between morning and afternoon: comparisons to variability of spirometric measurements. Acad Radiol. 2018; 25(12):1533-1539. 
[18] Washko GR1, Criner GJ, Mohsenifar Z, Sciurba FC, Sharafkhaneh A, Make BJ, et al. Computed tomographic-based quantification of emphysema and correlation to pulmonary function and mechanics. COPD. 2008; 5:177-186.

[19] Akira M, Toyokawa K, Inoue Y, Arai T. Quantitative CT in chronic obstructive pulmonary disease: inspiratory and expiratory assessment. AJR Am J Roentgenol. 2009; 192:267-272.

[20] Matsuoka S, Kurihara Y, Yagihashi K, Nakajima Y. Quantitative assessment of peripheral airway obstruction on paired expiratory/inspiratory thin-section computed tomography in chronic obstructive pulmonary disease with emphysema. J Comput Assist Tomogr. 2007;31:384-389.

[21] Orlandi I, Moroni C, Camiciottoli G, Bartolucci M, Belli G, Villari N,et al. Spirometric-gated computed tomography quantitative evaluation of lung emphysema in chronic obstructive pulmonary disease-a comparison of 3 techniques. J Comput Assist Tomogr. 2004; 28:437-442.

[22] Moher D, Liberati A, Tetzlaff J, Altman DG. Preferred reporting items for systematic reviews and metaanalyses: the PRISMA statement. Plos Med. 2009;339: 332-336.

[23] Whiting PF, Weswood ME, Rutjes AW, Reitsma JB, Bossuyt PN, Kleijnen J. Evaluation of QUADAS, a tool for the quality assessment of diagnostic accuracy studies. BMC Med Res Methodol. 2006;6:6-9.

[24] Crossley D, Renton M, Khan M, Low EV, Turner AM. CT densitometry in emphysema: a systematic review of its clinical utility. Am J Respir Crit Care Med. 2008; 13: 547-563.

[25] Xie X, de Jong PA, Oudkerk M, Wang Y, Ten Hacken NH, Miao J,et al. Morphological measurements in computed tomography correlate with airflow obstruction in chronic obstructive pulmonary disease: Systematic review and meta-analysis. Eur Radiol. 2012;22:2085-2093.

[26] Bon JM, Leader JK, Weissfeld JL, Coxson HO, Zheng B, Branch RA, et al.The influence of radiographic phenotype and smoking status on peripheral blood biomarker patterns in chronic obstructive pulmonary disease. PLoS One. 2009; 4:e6865.

[27] Dransfield MT, Washko GR, Foreman MG, Estepar RSJ, Reilly J, Bailey WC. Gender differences in the severity of CT emphysema in COPD. Chest. 2007; 132:464-470.

[28] Zhang Y, Tu YH, Fei GH. The COPD assessment test correlates well with the computed tomography measurements in COPD patients in China. Int J Chron Obstruct Pulmon Dis. 2015;10:507-14.

[29] Leader JK, Zheng B, Sciurba FC. The relation of airway size to lung function. Proc SPIE Med Imaging. 2008; 6916:691623.

[30] Lee YK, Oh YM, Lee JH, Kim EK, Lee JH, Kim N, et al .Quantitative assessment of emphysema, air trapping, and airway thickening on computed tomography. Lung. 2008; 186:157-165. 
[31] Park YS, Seo JB, Kim N, Chae EJ, Oh YM, Lee SD, et al.Texture-based quantification of pulmonary emphysema on high-resolution computed tomography: Comparison with density-based quantification and correlation with pulmonary function test. Invest Radiol. 2008; 43:395-402.

[32] Pauls S, Gulkin D, Feuerlein S, Muche R, Krüger S, Schmidt SA, et al.Assessment of COPD severity by computed tomography: correlation with lung functionaltesting. Clin Imaging. 2010;34:172-178.

[33] Washko GR1, Dransfield MT, Estépar RS, Diaz A, Matsuoka S, Yamashiro T, et al. Airway wall attenuation: a biomarker of airway disease in subjects with COPD. J Appl Physiol. 2009; 107:185-191.

[34] Yamashiro T, Matsuoka S, Bartholmai BJ, San José Estépar R, Ross JC, Diaz A, et al. Collapsibility of lung volume by paired inspiratory and expiratory CT scans. Correlations with lung function and mean lung density. Acad Radiol. 2010;17:489-495.

[35] Zhang J, Yu TL, Wu Q, Ye N, Cao Y, Zhou N.Quantitative MSCT study of lung attenuation in patients with chronic obstructive pulmonary disease. Chin J Med Imaging Technol. 2008;24:1611-1614 .

[36] Yamashiro T, Matsuoka S, Estépar RS, Dransfield MT, Diaz A, Reilly JJ, et al. Quantitative assessment of bronchial wall attenuation with thin-section CT: an indicator of airflow limitation in chronic obstructive pulmonary disease. Am J Roentgenol. 2010; 195:363-369.

[37] Hesselbacher SE, Ross R, Schabath MB, Smith EO, Perusich S, Barrow N, et al. Cross-sectional analysis of the utility of pulmonary function tests in predicting emphysema in ever-smokers. Int $\mathrm{J}$ Environ Res Public Health. 2011;8:1324-1340.

[38] Ohno Y, Koyama H, Yoshikawa T, Matsumoto K, Aoyama N, Onishi Y, et al. Comparison of capability of dynamic 02-enhanced MRI and quantitative thinsection MDCT to assess COPD in smokers. Eur J Radiol. 2011;81(5):1068-75.

[39] Iwasawa T, Takahashi H, Ogura T, Asakura A, Gotoh T, Shibata H, et al. Influence of the distribution of emphysema on diaphragmatic motion in patients with chronic obstructive pulmonary disease. Jpn J Radiol. 2011;29:256-64.

[40] Jin LF, Miao JT, Li ZY, Xie XQ, Dai XM. Study of voxel index from multislice CT in evaluating chronic obstructive pulmonary disease air-trapping. Chin J Med Imaging Technol. 207;23:1033-1036.

[41] Capaldi DP, Zha N, Guo F, Pike D, McCormack DG, Kirby M, et al.(2016) Pulmonary Imaging Biomarkers of Gas Trapping and Emphysema in COPD: (3)He MR Imaging and CT Parametric Response Maps. Radiology. 2016;279:597-608.

[42] Gawlitza J, Haubenreisser H, Henzler T, Akin I, Schönberg S, Borggrefe M,et al. Finding the right spot: Where to measure airway parameters in patients with COPD. Eur J Radiol. 2018;104:87-93. 
[43] Nishio, M. Nakane, K. Tanaka, Y. Validation of the homology method for emphysema quantification: Preliminary study. Int J Chron Obstruct Pulmon Dis. 2016; 11:2125-2137.

[44] Hoshino, M.Ohtawa, J. Computed tomography assessment of airway dimensions with combined tiotropium and indacaterol therapy in COPD patients. Respirology. 2014; 19(3):403-10.

[45] Ju J, Li R, Gu S, Leader JK, Wang X, Chen Y, et al. Impact of emphysema heterogeneity on pulmonary function. PLoS One. 2014;9(11):e113320.

[46] Saruya S, Matsuoka S, Yamashiro T, Matsushita S, Fujikawa A, Yagihashi K. et al. Quantitative CT measurements of small pulmonary vessels in chronic obstructive pulmonary disease: do they change on follow-up scans. Clin Physiol Funct Imaging. 2016; 36(3):211-7.

[47] Kim, S. S. Seo, J. B. Lee, H. Y. Chronic obstructive pulmonary disease: lobe-based visual assessment of volumetric $\mathrm{CT}$ by Using standard images-comparison with quantitative $\mathrm{CT}$ and pulmonary function test in the COPD Gene study. Radiology. 2013; 266:626-35.

[48] Kim EY, Seo JB, Lee HJ, Kim N, Lee E, Lee SM, et al. Detailed analysis of the density change on chest CT of COPD using non-rigid registration of inspiration /expiration CT scans. Eur Radiol. 2015; 25(2):5419 .

[49] Kundu S, Gu S, Leader JK, Tedrow JR, Sciurba FC, Gur D, et al. Assessment of lung volume collapsibility in chronic obstructive lung disease patients using CT. Eur Radiol. 2013; 23(6):1564-72.

[50] Kurashima K, Hoshi T, Takaku Y, Kanauchi T, Nakamoto K, Ueda M, et al.Changes in the airway lumen and surrounding parenchyma in chronic obstructive pulmonary disease. Int J Chron Obstruct Pulmon Dis. 2013;8:523-32.

[51] Lee SM, Seo JB, Lee SM, Kim N, Oh SY, Oh YM. Optimal threshold of subtraction method for quantification of air-trapping on coregistered CT in COPD patients. Eur Radiol. 2016; 26(7):2184-92.

[52] Haraguchi M, Nakamura H, Sasaki M, Miyazaki M, Chubachi S, Takahashi S, et al. Determinants of chronic obstructive pulmonary disease severity in the late-elderly differ from those in younger patients. BMC Res Notes. 2016; 4;9:7.

[53] Occhipinti M, Paoletti M, Bigazzi F, Camiciottoli G, Inchingolo R, Larici AR, et al. Emphysematous and Non emphysematous Gas Trapping in Chronic Obstructive Pulmonary Disease: Quantitative CT Findings and Pulmonary Function. Radiology. 2018; 287(2):683-692.

[54] Oh SY, Lee M, Seo JB, Kim N, Lee SM, Lee JS,et al.Size variation and collapse of emphysema holes at inspiration and expiration CT scan: evaluation with modified length scale method and image coregistration. Int J Chron Obstruct Pulmon Dis. 2017;13 (12):2043-2057. 
[55] Ohno Y, Onishi Y, Takenaka D, Matsumoto S, Nishimura Y, Sugimura K,et al. Comparison of capability of dynamic O(2)-enhanced MRI and quantitative thin-section MDCT to assess COPD in smokers. Eur J Radiol. 2012;81(5):1068-75.

[56] Karayama M, Inui N, Mori K, Kono M, Hozumi H, Suzuki Y,et al. Respiratory impedance is correlated with morphological changes in the lungs on three-dimensional CT in patients with COPD. Sci Rep. 2017; 8(7):41709.

[57] Sasaki T1, Takahashi K, Takada N, Ohsaki Y. Ratios of peripheral-to-central airway lumen area and percentage wall area as predictors of severity of chronic obstructive pulmonary disease. AJR Am J Roentgenol. 2014; 203:78-84.

[58] Šileikienè V, Urbonas M, Matačiūnas M, Norkūnienè J. Relationships between pulmonary function test parameters and quantitative computed tomography measurements of emphysema in subjects with chronic obstructive pulmonary disease. Acta Med Litu. 2017; 24(4):209-218.

[59] Timmins SC, Diba C, Farrow CE, Schoeffel RE, Berend N, Salome CM, et al. The relationship between airflow obstruction, emphysema extent, and small airways function in COPD. Chest. 2012;142(2):312-319.

[60] Wang G, Wang L, Ma Z, Zhang C, Deng K. Quantitative emphysema assessment of pulmonary function impairment by computed tomography in chronic obstructive pulmonary disease. J Comput Assist Tomogr. 2015; 39(2):171-5.

[61] Yahaba M, Kawata N, lesato K, Matsuura Y, Sugiura T, Kasai H, et al. The effects of emphysema on airway disease: correlations between multi-detector $\mathrm{CT}$ and pulmonary function tests in smokers. Eur $\mathrm{J}$ Radiol. 2014;83(6):1022-1028.

[62] Hasegawa M, Nasuhara Y, Onodera Y, Makita H, Nagai K, Fuke S, ,et al. Airflow limitation and airway dimensions in chronic obstructive pulmonary disease. Am J Respir Crit Care Med. 2006;15;173(12):130915.

[63] Camiciottoli G, Bartolucci M, Maluccio NM, Moroni C, Mascalchi M, Giuntini C, et al. Spirometrically gated high-resolution CT findings in COPD-lung attenuation vs lung function and dyspnea severity. Chest. 2006; 129(3):558-64.

[64] O'Donnell RA, Peebles C, Ward JA, Daraker A, Angco G, Broberg P, et al. Relationship between peripheral airway dysfunction, airway obstruction, and neutrophilic inflammation in COPD. Thorax. 2004;59(10):837-42.

[65] Zaporozhan J, Ley S, Eberhardt R, Weinheimer O, lliyushenko S, Herth F,et al. Paired inspiratory/expiratory volumetric thin-slice CT scan for emphysema analysis: comparison of different quantitative evaluations and pulmonary function test. Chest. 2005; 128(5):3212-20. 
[66] Washko GR, Diaz AA, Kim V, Barr RG, Dransfield MT, Schroeder J,et al. Computed tomographic measures of airway morphology in smokers and never-smoking normals. J Appl Physiol. 2014;15;116(6):668-73.

[67] Kim, V. Davey, A. Comellas, A. P. Clinical and computed tomographic predictors of chronic bronchitis in COPD: a cross sectional analysis of the COPD Gene study. Respir Res. 2014;15:52.

[68] Falaschi F, Miniati M, Battolla L, Filippi E, Sostman HD, Laiolo E,et al. Quantification of pulmonary emphysema with computerized tomography. Comparison with various methods. Radiol Med.1995; 90(12):16-23.

[69] Iwasawa T, Takahashi H, Ogura T, Asakura A, Gotoh T, Kagei S,et al.Correlation of lung parenchymal MR signal intensity with pulmonary function tests and quantitative computed tomography (CT) evaluation: a pilot study. J Magn Reson Imaging.2007;26(6):1530-6.

[70] Deveci F, Murat A, Turgut T, Altuntas E, Muz MH. Airway wall thickness in patients with COPD and healthy current smokers and healthy non-smokers: assessment with high resolution computed tomographic scanning. Respiration.2004;71(6):602-10.

\section{Figures}


2208 Citations identified from electronic database searching

1961 Cirations excluded based on title or abstract

247 Full-texts reviewed

130 Articles excluded based on full-text

1.Not suitable COPD sample

2.Not association between CT and PFT

117 Articles included in systematic review

36 Articles included in meta-analysis

81 Articles excluded from meta-analysis

1. Selection Bias

2. Small sample size

3. Not MDCT volume scan

4. No CT quantitative parameters included

5. No PFT parameters included

\section{Figure 1}

Flowchart of literature review and selection. COPD =Chronic obstructive pulmonary disease; PFT =Pulmonary function test; MDCT = Multi-detector computed tomography. 


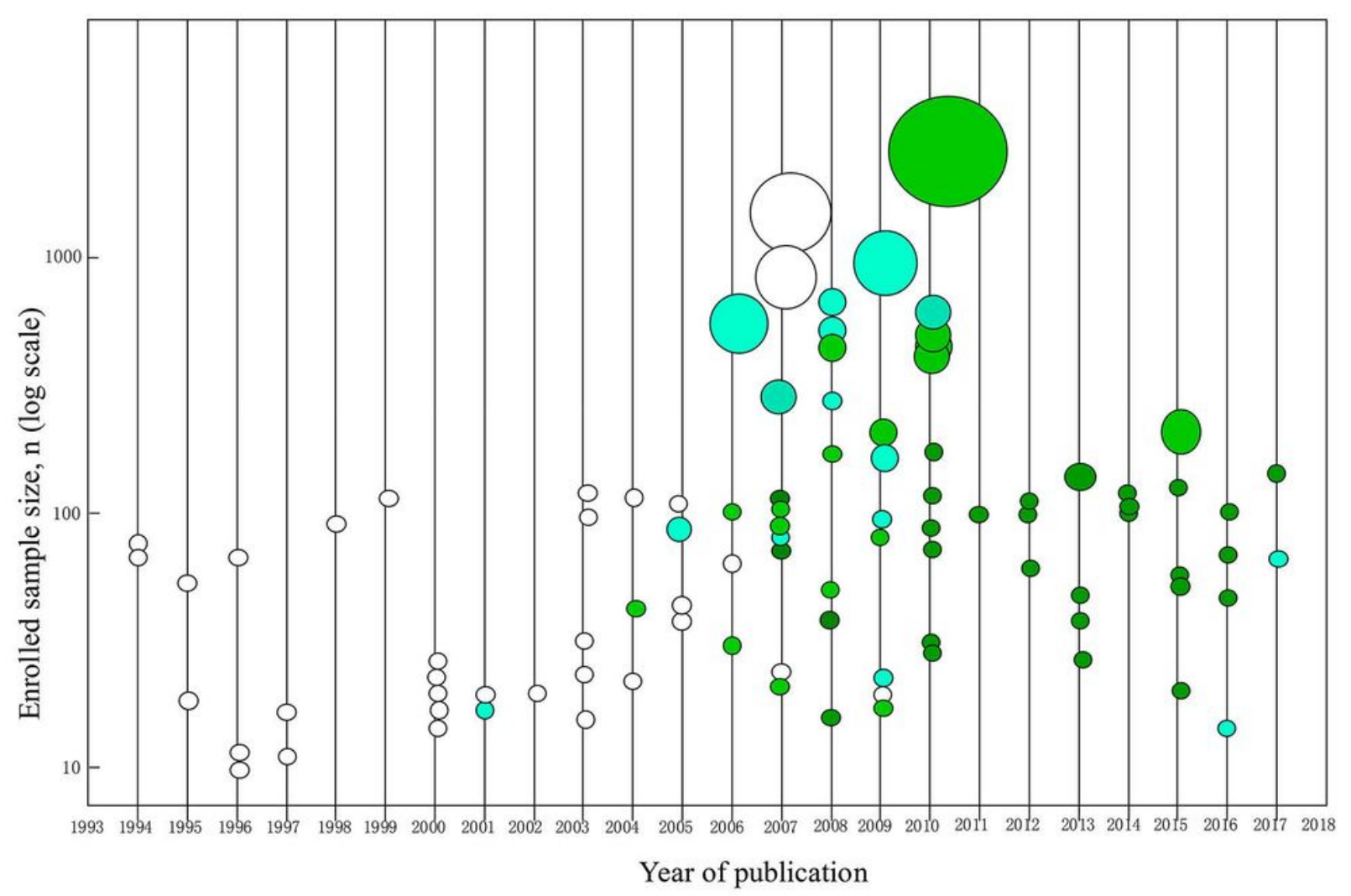

O Single slice CT

○ 4 to 8 slices CT

- 16 to 64 slices CT

\section{Figure 2}

Sample size of the articles included in the systematic review by year of publication and MDCT. MDCT = Multi-detector computed tomography 

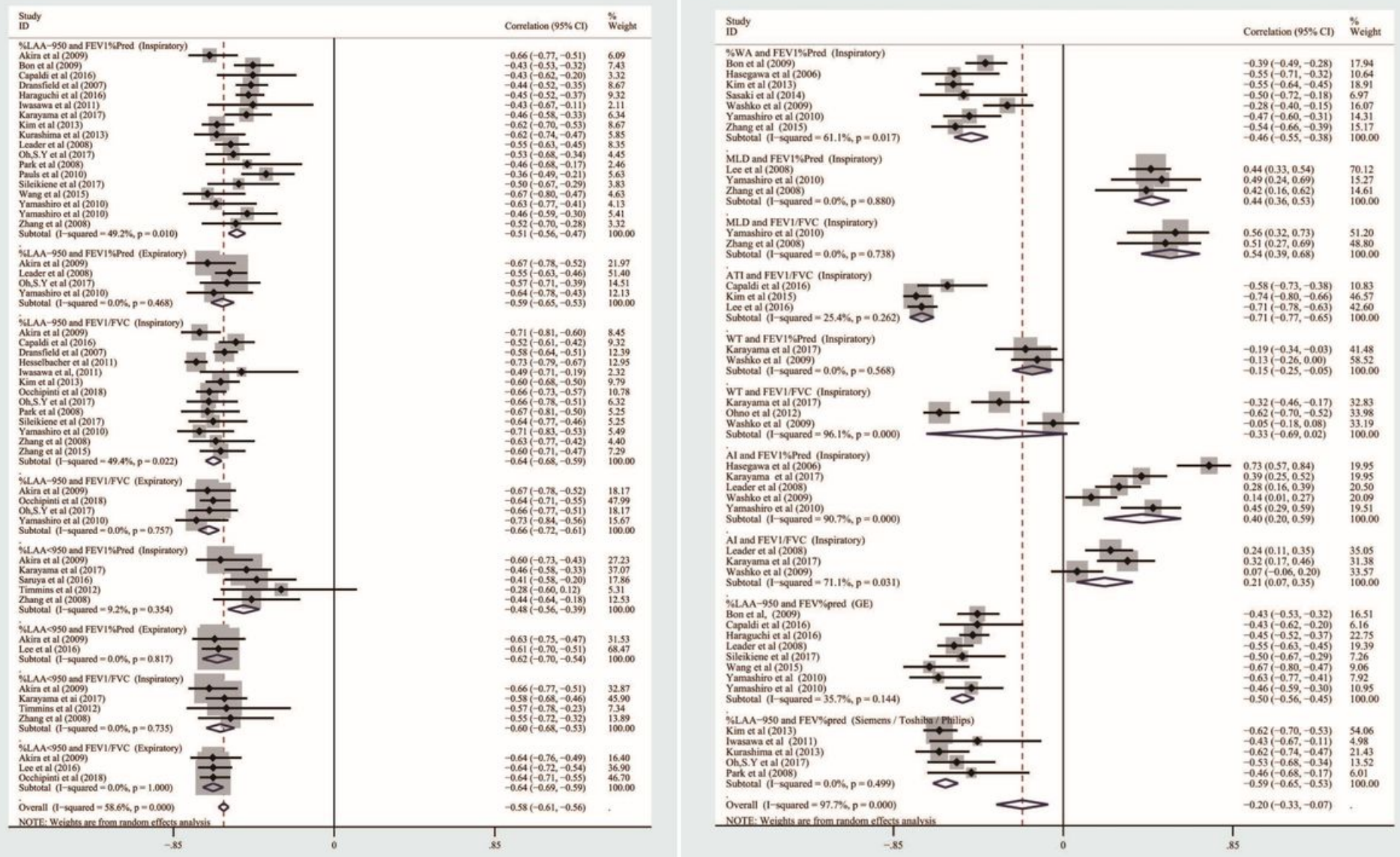

\section{Figure 3}

Forest plots for correlations between CT measurements and airflow obstruction.CCI = Confidence interval; $P(Z)=P$ value of $Z$ test; FEV1 \%pred = percentage of the predicted forced expiratory volume inthe first second; FEV1/FVC = FEV1 divided by forced vital capacity;\%LAA-950 = percentage lower attenuation area than $-950 \mathrm{HU} ; \mathrm{MLD}=$ =mean lung density; Perc15 = 15 percentile point of lung density; $\mathrm{WA} \%=$ wall area percentage

\section{Supplementary Files}

This is a list of supplementary files associated with this preprint. Click to download.

- supplement1.rtf

- supplement2.doc

- supplement3.rtf

- supplement4.jpg

- supplement5.jpg

- supplement6.rtf

- supplement7.doc

- supplement8.jpg 
- supplement9.doc

- supplement10.doc 